\title{
Artikel
}

\section{Personenschade en het verzekeringsrecht: tips \& tricks}

\author{
Mr. P.C. Knijp*
}

\section{Inleiding}

Het aansprakelijkheidsrecht en het verzekeringsrecht zijn de voor- en achterzijde van dezelfde medaille: de beide rechtsgebieden zijn nauw met elkaar verweven. Die verwevenheid komt in de wet op diverse plaatsen tot uitdrukking. Bijvoorbeeld in het aansprakelijkheidsrecht, waar artikel 3:287 BW een voorrecht in het leven roept op een aanspraak op uitkering onder een aansprakelijkheidsverzekering.

'De vordering tot vergoeding van schade is bevoorrecht op de vordering die de schuldenaar uit hoofde van verzekering van zijn aansprakelijkheid op de verzekeraar mocht hebben, voor zover deze vordering de verplichting tot vergoeding van deze schade betreft.'

Een tweede voorbeeld is artikel $6: 197 \mathrm{BW}$, waarin is bepaald dat sommige (risico)aansprakelijkheden niet op een verzekeraar kunnen overgaan krachtens subrogatie. Verder een voorbeeld van een verzekeringsrechtelijke bepaling die betrekking heeft op het aansprakelijkheidsrecht, is artikel 7:954 BW, waarin de directe actie van een personenschadeslachtoffer op de aansprakelijkheidsverzekeraar van de veroorzaker van de schade is geregeld.

Ondanks deze nauwe verwevenheid ligt in de juridische literatuur en de rechtspraak veelal de nadruk op het aansprakelijkheidsvraagstuk. Ook de schadeomvang houdt

* Mr. P.C. (Peter) Knijp is als advocaat verbonden aan Stadermann Luiten Advocaten te Rotterdam. de juridische gemoederen flink bezig. ${ }^{1}$ En hoewel ik mij haast om aan te geven dat dit niet op wetenschappelijk statistisch onderzoek gebaseerd is, heb ik de indruk dat het verzekeringsrecht veel minder in de belangstelling staat, zeker in relatie tot personenschade. ${ }^{2}$ Dat is misschien wel begrijpelijk, als we ervan uitgaan dat de voorzijde van de medaille het aansprakelijkheidsrecht is en het verzekeringsrecht de achterzijde, maar onbekend maakt misschien ook onbemind.

Wat daarvan verder ook zij, het aansprakelijkheidsrecht kan in de praktijk niet goed zonder het verzekeringsrecht, en vice versa. In de praktijk valt echter waar te nemen dat sommige verzekeringsrechtelijke aspecten nog wel eens wat uit het oog worden verloren. In deze bijdrage zal ik daarom een paar op het verzekeringsrecht georiënteerde 'tips \& tricks' aandragen die van belang kunnen zijn bij de verkriiging van schadevergoeding in personenschadegevallen.

1. Zie bijvoorbeeld de actuele discussie rondom de rekenrente in de bijdrage 'De redelijke verwachting ten aanzien van de rekenrente' van de hand van R.M.J.T. van Dort \& E.S. Groot, TVP 2019, nr. 3, p. 84 e.v. Interessant zijn ook de ontwikkelingen op het snijvlak van het strafrecht en het civiele aansprakelijkheidsrecht; zie daarvoor bijvoorbeeld $\mathrm{H}$. de Hek, 'Schadevergoeding voor dummies', in TAP 2019, nr. 2.

2. De meest spraakmakende uitspraak op het snijvlak van het verzekeringsrecht en de personenschade van de laatste jaren is, wat mij betreft, de uitspraak van de HR van 13 april 2018, ECLI:NL:HR:2018:601. Dit betrof het geval waarin een vader zijn kind - een baby nog - ernstig hersenletsel toebracht. De moeder sprak in haar hoedanigheid van vertegenwoordiger van het kind de aansprakelijkheidsverzekeraar van de vader aan tot vergoeding van de schade. De verzekeraar beriep zich op de zogeheten 'opzetuitsluiting' in de polis. 


\section{Het voorbeeld: de case Suares}

De 'tips \& tricks' die het onderwerp van deze bijdrage zijn, worden vooral inzichtelijk aan de hand van een praktijkvoorbeeld; het gaat om de casus die ten grondslag lag aan het arrest Excellent/Suares. ${ }^{3}$

Suares was in dienst bij uitzendbureau Excellent. Door Excellent was hij uitgezonden naar Ebrex. Tijdens de uitvoering van de hem door Ebrex opgedragen werkzaamheden werd hij, terwijl hij zelf een bromfiets bestuurde, op een terrein in de Rotterdamse haven overreden door een reachstacker ${ }^{4}$ Hij liep daardoor ernstig letsel op. De reachstacker was weer eigendom van en in gebruik bij een ander bedrijf en de bestuurder was in dienst van dat andere bedrijf.

Suares koos ervoor - ongetwijfeld daartoe geadviseerd door zijn advocaat - om Excellent aan te spreken. Met in het achterhoofd dat de arresten van de Hoge Raad van 1 februari $2008^{5}$ en 12 december $2008^{6}$ over de verzekeringsplicht van de werkgever nog niet waren gewezen, ${ }^{7}$ was dit op zichzelf een goed advies. Bezien vanuit de aansprakelijkheidsvraag was het antrekkelijk om de werkgever aan te spreken. Immers, een beroep op eigen schuld is bij werkgeversaansprakelijkheid niet mogelijk en de regeling van artikel 7:658 BW bevat een aantrekkelijk bewijsregime. Het alternatief - het aanspreken van de bestuurder, de eigenaar of de werkgever van de reachstacker - was minder antrekkelijk, aangezien er dan een discussie zou zijn gevolgd over eigen schuld; Suares had mogelijk een bocht te ruim genomen, hetgeen mede causaal geweest had kunnen zijn voor het ontstaan van het ongeval. ${ }^{8}$

De route naar de aansprakelijkheid van de formeel werkgever, Excellent, liep via de Hoge Raad, omdat deze een uitspraak moest doen over de vraag of de formele werkgever (het uitzendbureau) ook ansprakelijk is voor het niet-nakomen van de verplichtingen van artikel 7:658 BW door de materiële werkgever (de inlener). Het eindresultaat was positief: Excellent was volledig jegens Suares aansprakelijk. Tot zover het aansprakelijkheidsrechtelijke deel van de casus.

Maar dit alles leverde Suares geen schadevergoeding op. Weliswaar had Excellent namelijk wel een 'gewone' aan-

HR 4 oktober 2002, ECLI:NL:HR:2002:AE4080 (Uitzendbureau Excellent/Suares).

4. Een reachstacker is een groot voertuig dat bestemd is om zeecontainers te tillen, te verplaatsen en te stapelen.

5. HR 1 februari 2008, ECLI:NL:HR:2008:BB6175.

6. HR 12 december 2008, ECLI:NL:HR:2008:BD3129.

7. In die arresten legde de Hoge Raad de op art. 7:611 BW gebaseerde verzekeringsplicht van de werkgever neer, die geldt voor zowel fietsende als met gemotoriseerde vervoermiddelen aan het verkeer deelnemende werknemers. Alleen te voet aan het verkeer deelnemende werknemers vallen nog buiten het beschermingsbereik van art. 7:611 BW.

8. Omdat Suares reed op een bromfiets, viel hij niet onder de reikwijdte (en dus bescherming) van de risicoaansprakelijkheid van art. 185 WVW. sprakelijkheidsverzekering, ${ }^{9}$ maar die bevatte - zoals bij aansprakelijkheidsverzekeringen gebruikelijk is - de zogeheten motorrijtuigenuitsluiting en dekte dus niet 'schade, veroorzaakt met of door een motorrijtuig'. En Excellent bood zelf nauwelijks of geen verhaal. Uiteindelijk kwam het goed, maar dat was op het nippertje. Excellent begon namelijk een procedure tegen haar eigen verzekeraar, waarin zij uitkering vorderde onder haar aansprakelijkheidsverzekering. Die procedure mondde uit in de uitspraak van de Hoge Raad van 13 juli $2007 .{ }^{10}$ In deze uitspraak legde de Hoge Raad het begrip 'spiegelbeelddekking' nader uit. Het begrip spiegelbeelddekking heeft betrekking op de gedachte dat de dekking onder een 'gewone' aansprakelijkheidsverzekering moet aansluiten op de dekking van een WAM-verzekering $;{ }^{11}$ wat onder de ene verzekering is gedekt, zou uitgesloten moeten zijn onder de andere verzekering. De 'gewone' aansprakelijkheidsverzekering sluit schade, veroorzaakt met of door een motorrijtuig, van dekking uit, zoals hiervoor al aangegeven. Voor die ansprakelijkheden is een motorrijtuigenverzekering bedoeld. Wat onder de ene verzekering dus niet is gedekt, is - idealiter-onder de andere verzekering wel gedekt.

In sommige gevallen is er evenwel helemaal geen andere verzekering, zoals in het geval van uitzendbureau Excellent. Excellent had immers alleen een AVB. Zij kon zelf geen WAM-verzekering voor de reachstacker afsluiten, angezien zij daarvan niet de eigenaar was. De Hoge Raad oordeelde in de procedure tussen Excellent en haar verzekeraar dat in dit geval de gedachte van de spiegelbeelddekking zou betekenen dat het onderhavige risico voor Excellent onverzekerbaar zou zijn - en dat is niet de bedoeling. De aansprakelijkheidsverzekeraar van Excellent zegde vervolgens alsnog dekking toe. Eind goed, al goed dus, althans wat betreft de schadevergoeding van Suares, maar de route was lang en voerde tweemaal vlak langs een afgrond.

Dit voorbeeld uit de praktijk brengt mij tot de volgende tips.

\section{Breng alle mogelijke aansprakelijke partijen} in kaart - maak een plattegrond!

De moraal van het verhaal van de casus van Excellent/ Suares is dat de makkelijkste weg vanuit aansprakelijkheidsrechtelijk perspectief niet altijd de makkelijkste weg naar een zo snel en/of volledig mogelijke schadevergoeding hoeft te zijn. De eerste tip: probeer zo goed en helder mogelijk de verhoudingen tussen partijen in beeld te brengen. Maak daarom een 'plattegrond' - een fysieke tekening - en doe het volgende:

9. Een AVB ('aansprakelijkheidsverzekering voor bedrijven'). De particuliere variant heet 'AVP' ('aansprakelijkheidsverzekering voor particulieren').

10. HR 13 juli 2007, ECLI:NL:HR:2007:BA7217.

11. Een WAM-verzekering is verplicht voor voertuigen waarmee op de openbare weg of 'een terrein' wordt gereden; de verzekeringsplicht rust op de eigenaar. Dikwijls is de WAM-dekking ingebed in een verzekering die 'landmateriaal-verzekering' wordt genoemd. Het gaat dan om een verzekering voor voertuigen, zoals shovels, graafmachines, vorkheftrucks en ook reachstackers, zoals in de kwestie van Suares. Meestal is onder die verzekeringen zowel het werk- als het verkeersrisico gedekt. 
Figuur 1

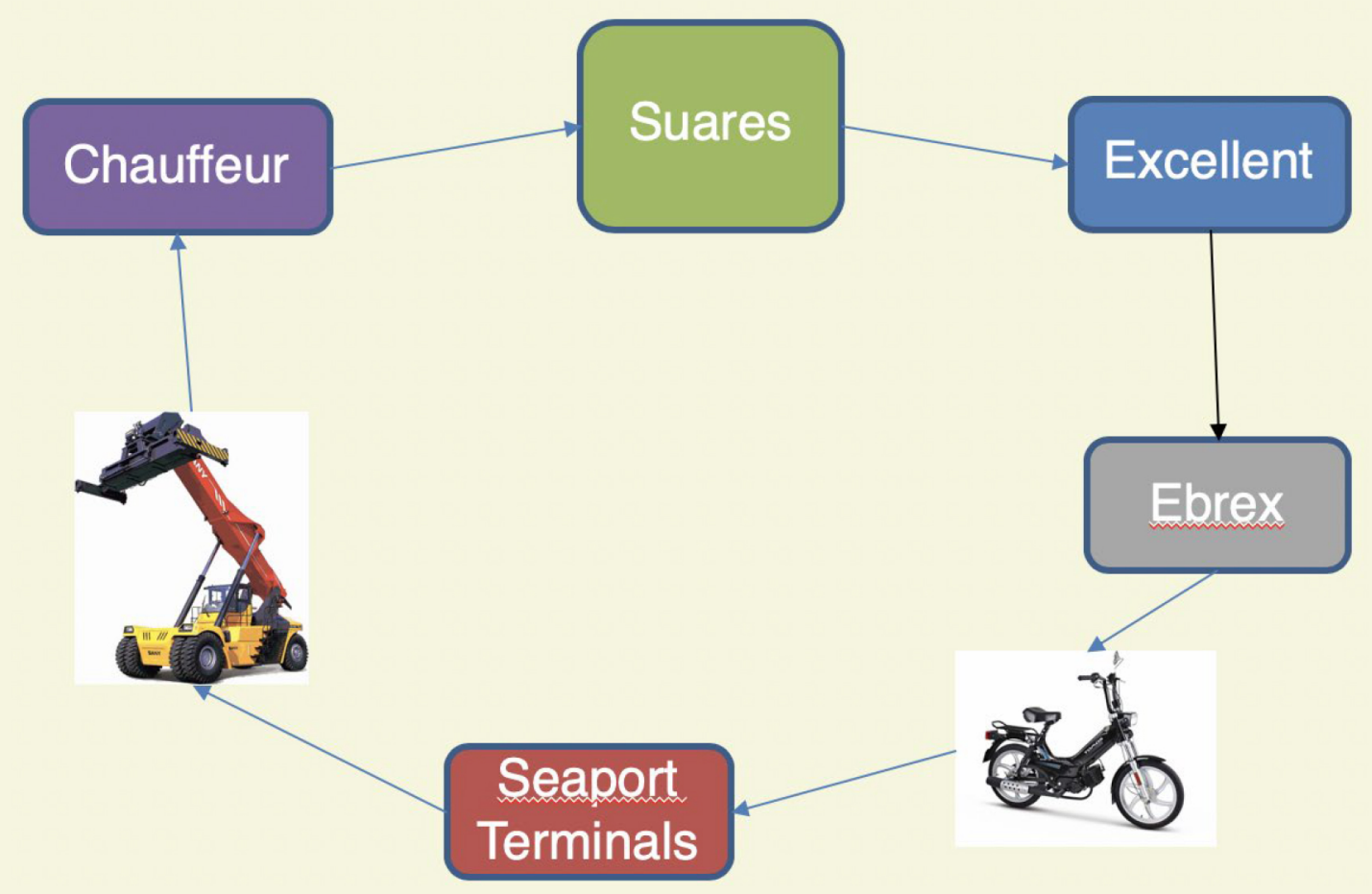

Figuur 2

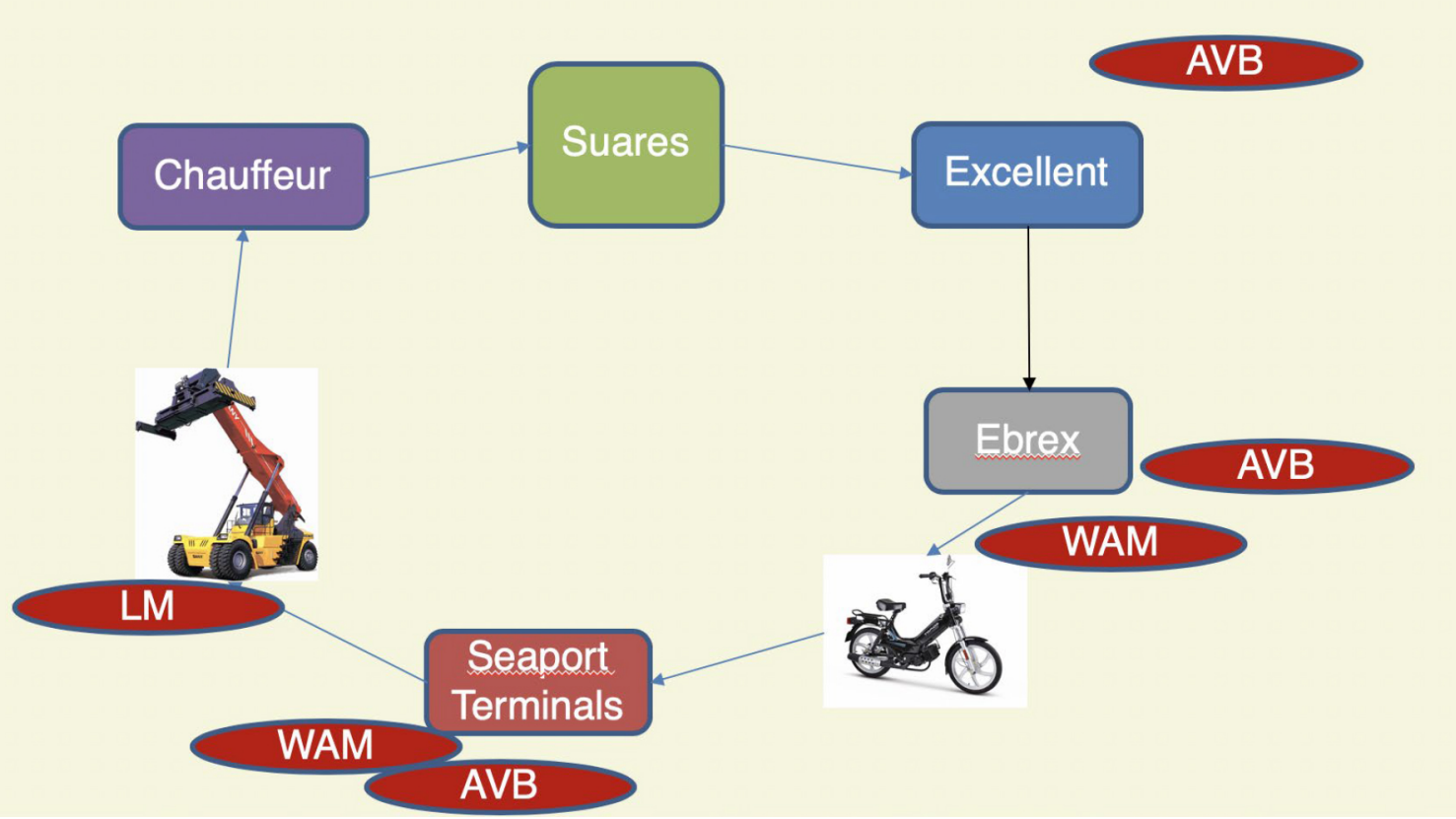

- Breng alle aansprakelijke partijen in kaart en teken de verhoudingen in.

- Breng vervolgens alle (mogelijke) verzekeringen in kaart.

- Informeer bij (mogelijke) aansprakelijke partijen naar de vraag of zij dekking onder een verzekering hebben.

Dit voorkomt dat je aan het eind van een lange procedure met lege handen staat, omdat de partij die aanspra-

kelijk is geen verhaal blijkt te bieden. Een plattegrond zou er, in het geval van Ecellent/Suares, uit kunnen zien als in Figuur 1.

Nemen we alle mogelijke verzekeringen in ogenschouw, dan wordt het plaatje zoals in Figuur 2.

Het is natuurlijk niet noodzakelijk dat een schets of plattegrond perfect is; het gaat erom dat visueel inzichtelijk wordt hoe de verhoudingen liggen. Met de verzekerin- 
gen (in Figuur 2 in de rode cirkels, waarbij 'LM' staat voor 'Landmaterieelverzekering') wordt ook duidelijk welke partij voor welk aansprakelijkheidsrisico verzekerd zal (of kan) zijn.

En dat brengt ons bij de volgende tip.

2. Bedenk welke polis waarvoor dekking biedt. Natuurlijk was de kwestie van Excellent/Suares een uitzonderlijke zaak. Niet alleen omdat twee procedures tot aan de Hoge Raad nodig waren, maar ook omdat daarin sprake was van verschillende (mogelijk) aansprakelijke partijen die ook nog in allerlei complexe contractuele en buitencontractuele verhoudingen tot elkaar stonden. Een geval zoals dat van dhr. Suares is echter niet uitzonderlijk. Met de opkomst van de interneteconomie en de daarmee gepaard gaande 'thuiswinkeleconomie' groeit ook het aantal distributiecentra, waarin allerlei verkeersbewegingen plaatsvinden en werknemers op gemotoriseerde voertuigen én te voet hun werk moeten doen; het aantal ongevallen op de werkvloer, waarbij gemotoriseerde voertuigen betrokken zijn, lijkt dan ook een stijgende lijn te vertonen.

Het is daarom van belang om voorafgaand aan de keuze welke partij aan te spreken, helder voor ogen te hebben welke aansprakelijkheid onder welke verzekering is gedekt. Grofweg zijn er vier van elkaar te onderscheiden vormen van aansprakelijkheidsverzekeringen en één 'vreemde eend in de bijt'-verzekering:

- De 'gewone' AVB (of AVP). Deze dekt in beginsel de aansprakelijkheid van artikel 7:658 $\mathrm{BW}$, maar niet schade die is veroorzaakt 'met of door een motorrijtuig'.

- De WAM-verzekering. Deze dekt de schade die is veroorzaakt met een motorrijtuig in het verkeer, het zogeheten 'verkeersrisico'.

- De landmateriaalverzekering. Deze verzekering dekt in principe het werkrisico dat aan het te verzekeren motorrijtuig is verbonden. Denk daarbij aan de graafmachine waarmee tijdens het graven kabels kapot worden getrokken, of de hoogwerker die omvalt en schade veroorzaakt. In de meeste gevallen is een landmaterieelverzekering voorzien van een zogeheten 'wam-strik', waarmee de dekking ook naar het verkeersrisico wordt uitgebreid.

- De Wegas/Wegam-verzekering. Deze afkorting staat voor 'werkgeversaansprakelijkheid motorrijtuigen'. Met deze verzekering wordt de aansprakelijkheid van de werkgever voor schade gedekt die is veroorzaakt met of door een motorrijtuig. Deze verzekeringsvorm is na het arrest Vonk/Van der Hoeven ${ }^{12}$ bedacht.

- Tot slot de vreemde eend in de bijt: de SVI - wat staat voor 'schadeverzekering inzittenden'. Deze verzekeringsvorm is niet zozeer een aansprakelijkheidsverzekering, maar biedt in sommige gevallen een gefixeerde dekking voor schade die door de bestuurder en/of de inzittenden van een verzekerd

12. HR 12 januari 2001, ECLI:NL:HR:2001:AA9434 (Vonk/Van der Hoeven). voertuig wordt geleden; in andere gevallen is in de polis(voorwaarden) bepaald dat de schade, berekend op basis van artikel 6:107 $\mathrm{BW}$, is gedekt.

- Omdat deze laatste verzekeringsvorm geen aansprakelijkheidsverzekering is, zijn buitengerechtelijke kosten - in de praktijk niet zelden een heet hangijzer in de schadeafwikkeling - daaronder in principe niet verzekerd (tenzij de polis of de polisvoorwaarden anders bepalen). Het is verstandig daarmee in de praktijk rekening te houden.

\section{Bedenk dat 'verzekeringnemer' en 'verzekerde' twee verschillende begrippen zijn.}

De eigenaar van een motorrijtuig is degene die verplicht is voor dat motorrijtuig (als daarmee op de weg of op een terrein wordt gereden) een WAM-verzekering af te sluiten. Dikwijls is de eigenaar van het motorrijtuig, als daarmee een ongeval wordt veroorzaakt, niet de aansprakelijke partij. Dat is eigenlijk alleen het geval als de aansprakelijkheid wordt gebaseerd op (de risicoaansprakelijkheid van) artikel $185 \mathrm{WVW}$. En daarvoor is vereist dat een niet-gemotoriseerde verkeersdeelnemer schade lijdt als gevolg van een ongeval dat met het motorrijtuig veroorzaakt wordt op de weg. ${ }^{13}$ In een dergelijk geval heeft het dus geen zin de eigenaar van het voertuig aan te spreken als de eigenaar niet ook inhoudelijk een verwijt te maken valt (of deze bijvoorbeeld niet ook op grond van art. 6:170 BW aansprakelijk is).

Dit lijkt een nogal theoretische uiteenzetting, maar in de praktijk komt het dikwijls voor dat het 'rollend materieel' dat in gebruik is bij een onderneming niet het eigendom is van die onderneming; vaak wordt het landmaterieel (de vorkheftrucks, orderpickers, etc.) gehuurd of geleased. In die situatie is de eigenaar (de verhuurder, de leasemaatschappij, etc.) dus de verzekeringnemer die de landmaterieel- of WAM-verzekering afsluit; de gebruiker zal dan in de regel verzekerde onder die polis zijn. Bij een ongeval waarbij dus in bijvoorbeeld een magazijn met een geleasede vorkheftruck letselschade wordt veroorzaakt, is het niet zinvol de leasemaatschappij aan te spreken. Het is dan zaak om aan de hand van de polis en de polisvoorwaarden te bezien of (bijvoorbeeld) de werkgever verzekeringsdekking heeft voor diens (eventuele) aansprakelijkheid voor fouten van een ondergeschikte (art. 6:170 BW).

\section{Ga na wie de verzekeraar is.}

Het klinkt als een open deur, maar het is natuurlijk om voor de hand liggende redenen praktisch om te weten wie de aansprakelijkheidsverzekeraar is. Wie dat is, is in veel gevallen evident, maar dat is het lang niet altijd. Bijvoorbeeld in het geval waarin een leasemaatschappij of landmaterieelverhuurbedrijf een groot wagenpark

13. De definitie van 'wegen' als bedoeld in de WVW luidt: 'alle voor het openbaar verkeer openstaande wegen of paden met inbegrip van de daarin liggende bruggen en duikers en de tot die wegen behorende paden en bermen of zijkanten'; zie art. 1 sub b WVW. Op ongevallen met motorrijtuigen in bijvoorbeeld een distributiecentrum, of op een afgehekt terrein, is art. 185 WVW a priori niet van toepassing. 
verzekert; dergelijke verzekeringen worden vaak via de assurantiebeurs of in co-assurantie gesloten. De polis wordt in dergelijke gevallen niet zelden ondertekend door de verzekeringsmakelaar of gevolmachtigde. Dit luistert nauw; als in een dergelijk geval een op artikel 7:954 BW gebaseerde vordering wordt gericht tegen deze ondertekenaar - die dus niet de verzekeraar is dan is de vordering gedoemd te mislukken.

Als niet direct duidelijk is wie de op de polis betrokken verzekeraars zijn, dan is het zaak om daar navraag naar te doen. Dat kan door bij de makelaar, of de aansprakelijk gestelde verzekerde, een zogeheten 'maatschappijverdeling' op te vragen. In dit document wordt aangegeven wie de betrokken verzekeraar(s) is (of zijn), en in het geval dit er meer dan één betreft, voor welk aandeel zij op de polis betrokken zijn. De desbetreffende verzekeraars zijn dan alleen voor hun eigen aandeel aan te spreken en - belangrijk! - moeten, als het zover komt, allemaal voor dat aandeel worden mee gedagvaard.

Een goede vuistregel is dat in Nederland een bv nooit een verzekeraar kan zijn. Als een polis dus ondertekend is door een bv, is dat waarschijnlijk de verzekeringsmakelaar of gevolmachtigde en is het zaak om na te gaan wie de verzekeraar(s) is (of zijn).

Het is mogelijk dat de partij aan wie inzage in of afschrift van de verzekeringspolis en verzekeringsvoorwaarden is verzocht, weigert deze te verstrekken. In dat geval kan inzage in de polisbescheiden worden afgedwongen door dit in kort geding te vorderen, bij voorkeur op de grondslag van artikel $843 \mathrm{a} \mathrm{Rv}$. In dit artikel is de bijzondere exhibitieplicht geregeld. Voor toewijzing van een dergelijke vordering moet voldaan zijn aan drie cumulatieve vereisten, namelijk (1) de eiser moet een rechtmatig belang hebben, (2) het moet gaan om bepaalde bescheiden en (3) de eiser moet partij zijn bij de rechtsbetrekking waarop de bescheiden betrekking hebben. In situaties als bedoeld in deze bijdrage - bijvoorbeeld de hierna te bespreken vordering die is gebaseerd op artikel 7:954 BW - zal al snel aan deze voorwaarden zijn voldaan.

\section{Vergeet niet bij een artikel 7:954 BW- vordering de aansprakelijke verzekerde partij mee te dagvaarden/rekwestreren.}

Het is sinds 2006 mogelijk om in gevallen waarin sprake is van letsel- of overlijdensschade een rechtstreekse vordering in te stellen tegen de aansprakelijkheidsverzekeraar van de aansprakelijke partij. Dat gebeurt inmiddels in de praktijk regelmatig.

Wat echter ook dikwijls gebeurt, is dat vergeten wordt de aansprakelijke partij mee op te roepen. Zie HR 1 februari 2019 voor gevallen waarin dat niet nodig is of niet (meer) kan; ${ }^{14}$ zie voor een uitgebreide uiteenzetting van gevallen over het vereiste dat de schade door de verzekerde onder de aansprakelijkheidsverzekering moet zijn gemeld, de conclusie van de A-G bij dat arrest - op dat vereiste zal ik hier niet nader ingaan.

14. HR 1 februari 2019, ECLI:NL:HR:2019:150; zie voorts K.C.A. Schweers, 'De uitzondering op het meldingsvereiste in art. 7:954 lid 2 BW nader uitgelegd, NTHR 2019-4.
De sanctie die op dit verzuim om de verzekerde mee op te roepen staat, is niet-ontvankelijkheid. ${ }^{15}$ In sommige gevallen echter wordt de eiser die zich schuldig maakt aan dit verzuim, gered door de rechter. Bijvoorbeeld in de uitspraak van de Rechtbank Den Haag van 19 december 2012, ${ }^{16}$ waarbij opmerking verdient dat in de zaak die aan die uitspraak ten grondslag lag geen sprake was van verzekeringsrechtelijke complicaties. Maar het is natuurlijk veel verstandiger om het niet an te laten komen op de welwillendheid van de rechter, maar ervoor te zorgen dat aan de formele vereisten is voldaan. Neem dus het zekere voor het onzekere en roep de verzekerde tijdig op.

\section{Afronding}

Ik begon deze bijdrage met de opmerking dat het verzekeringsrecht en het aansprakelijkheidsrecht met elkaar verweven zijn, en met diezelfde constatering zou ik willen afronden.

De vijf bovenstaande aandachtspunten laten zich, in de kern genomen, ook als volgt samenvatten: probeer zo helder mogelijk te krijgen hoe de vork in de steel zit. Dat bevordert een snelle en efficiënte afwikkeling, en dat is in het belang van alle betrokken partijen.

15. Zie hierover ook M. van Tiggele, 'Kroniek directe actie ex 7:954 BW. From thought to de Hoge Raad', in AV\&S 2019/18.

16. Rb. Den Haag 19 december 2012, ECLI:NL:RBSGR:2012:BZ2046, zie ook Van Tiggele, t.a.p. 